\title{
SISTEM PAKAR DENGAN METODE FORWARD CHAINING UNTUK MENENTUKAN PEMBAGIAN WARISAN MENURUT HUKUM ISLAM MENGGUNAKAN ALGORITMA BEST FIRST SEARCH
}

\author{
Anton Setiawan H. ${ }^{1}$, Yuliani Indrianingsih ${ }^{2}$, Anis Syaul Umami ${ }^{3}$ \\ Program Studi Teknik Informatika \\ Sekolah Tinggi Teknologi Adisutjipto Yogyakarta \\ anton@stta.ac.id'1 ,yulistta@gmail.com², Anissyaul27@gmail.com ${ }^{3}$
}

\begin{abstract}
In Islamic law, the division of inheritance according to the provisions of Islamic rule is an obligation. It is encouraged to immediately distribute inheritance without delaying. The manual process of dividing inheritance according to islamic law requires a lot of time and expertise, which is not everyone capable of. So there is a need for providing an expert system for dividing inheritance according to Islamic law that can help people to hasten the implementation of Islamic sharia in distributing inheritance. This expert system is a web-based system. Transformation of expertise knowledge in this expert system uses forward chaining method with best first search algorithm. The result of the consultation on this expert systemconsist of the complete profile data of the deceased, the blocked-heirs, the portion for each heir and the portion of the inheritance for each heir.
\end{abstract}

Keywords : Division of Inheritance, Expert System, Forward Chaining, Best First Search.

\section{Pendahuluan \\ a. Latar Belakang}

Menurut Abdurrahman (2016), Pembagian waris adalah menentukan bagian setiap ahli waris atas harta waris sesuai ketentuan syariah. Artinya, secara syar'i setiap ahli waris hanya berhak atas bagian yang menjadi haknya sesuai dengan bagian yang ditentukan oleh hukum-hukm waris. Hukum waris pada hakikatnya mengatur pemindahan kepemilikan harta warisan dari orang yang sudah meninggal kepada ahli warisnya. Ahli waris yaitu orang yang memiliki hubungan darah (nasab), pernikahan yang sah, pembebasan budak dan wasiat. Syarat menjadi ahli waris harus sama-sama beragama Islam baik ahli waris dan orang yang mewariskan. Orang yang mewariskan adalah orang yang secara riil sudah meninggal atau secara hukum sudah meninggal.

Dalam Islam pembagian harta warisan sesuai dengan ketentuan syariah adalah wajib hukumnya. Menurut syariah sebaiknya harta warisan segera dibagi dan tidak ditunda-tunda. Membagi waris pada dasarnya adalah menentukan berapa bagian setiap ahli waris atas harta warisan, dilanjutkan dengan membagi harta warisan secara riil dengan menentukan mana yang menjadi bagian setiap ahli waris dan menyerahkan kepada setiap ahli waris itu kekuasaan atas harta yang menjadi bagiannya. Menurut Kusumadewi (2003), Sistem pakar adalah sistem yang berusaha mengadopsi pengetahuan manusia ke komputer, agar komputer dapat menyelesaikan masalah seperti yang biasa dilakukan oleh ahli. Penelitian ini mengusulkan pembangunan aplikasi sistem pakar untuk pembagian harta waris. Sistem transformasi pengetahuan kepakaran pada sistem pakar ini menggunakan metode pelacakan kedepan (Forward Chaining) dengan algoritma Best First Search. Tujuan pembangunan aplikasi sistem pakar ini diharapkan dapat membantu masyarakat membagi harta warisan. 


\section{Landasan Teori}

\subsection{Sistem Pakar}

Menurut Kusumadewi (2003), Sistem pakar adalah sistem yang berusaha mengadopsi pengetahuan manusia ke komputer, agar komputer dapat menyelesaikan masalah seperti yang biasa dilakukan oleh ahli

Menurut Desiani dkk (2006), sistem pakar adalah cabang dari kecerdasan buatan (Artificial Intelligence) dan sistem yang bekerja untuk mengadopsi pengetahuan manusia ke komputer yang menggabungkan dasar pengetahuan (knowledge base) dengan sistem inferensi untuk menggantikan fungsi seorang pakar dalam menyelesaikan suatu masalah.

\subsection{Arsitektur Sistem Pakar}

Menurut Kusumadewi (2003), Sistem pakar terdiri dari dua bagian pokok yaitu, lingkungan pengembangan dan lingkungan konsultasi. Lingkungan pengembangan digunakan sebagai pembangun sistem pakar baik dari segi pembangun komponen maupun basis pengetahuan. Lingkungan konsultasi digunakan oleh seseorang yang bukan ahli untuk berkonsultasi.

Komponen - komponen yang ada pada sistem pakar adalah

1. Substansi penambahan pengetahuan. Bagian ini digunakan untuk memasukkan pengetahuan, mengkontruksi atau memperluas pengetahuan dalam basis pengetahuan.

Pengetahuan ini bisa berasal dari : ahli, buku, basisdata, penelitian, dan gambar.

2. Basis pengetahuan ialah berisi pengetahuan untuk memahami, merumuskan, memecahkan masalah.

Motor Inferensi (inference engine). Program yang berisi metodologi yang digunakan untuk melakukan penalaran terhadap informasi-informasi dalam basis pengetahuan dan blackboard, serta digunakan untuk menformulasikan konklusi. Ada tiga elemen utama dalam motor inferensi, yaitu:

1. Interpreter : mengeksekusi item-item agenda yang terpilih dengan menggunakan aturan-aturan dalam basis pengetahuan yang sesuai.

2. Scheduler : akan mengontrol agenda.

3. Consistency enforcer : akan berusaha menjaga kekonsistenan dalam merepresentasikan solusi yang bersifat darurat.

4. Blackboard merupakan area dalam memori yang digunakan untuk merekam kejadian yang sedang berlangsung termasuk keputusan sementara. Ada tiga tipe keputusan yang dapat direkam yaitu:

5. Rencana : Bagaimana menghadapi masalah

6. Agenda : aksi-aksi yang potensial yang sedang menunggu untuk dieksekusi

7. Solusi : calon aksi yang akan dibangkitkan

8. Antar muka digunakan untuk media komunikasi antara pemakai dengan program.

9. Subsistem penjelasan digunakan untuk melacak respon dan memberikan penjelasan tentang kelakuan sistem pakar secara interaksif melalui pertanyaan.

Sistem penyaring pengetahuan. Sistem yang digunakan untuk mengevaluasi kinerja sistem pakar itu sendiri untuk melihat apakah pengetahuan yang ada masih cocok untuk digunakan dimasa mendatang.

\subsection{Metode Forward Chaining}

Menurut Wilson (1998), Metode Forward Chaining berarti menggunakan himpunan aturan kondisi-aksi. Dalam metode ini, data digunakan untuk menentukan aturan mana yang akan dijalankan, kemudian aturan tersebut dijalankan. Mungkin proses penambahan data ke memori kerja. Proses diulang sampai ditemukan suatu hasil.

\subsection{Algoritma Best First Search}

Menurut Suyanto (2014), Sesuai dengan namanya Best First Search adalah pelacakan yang membangkitkan simpul berikutnya dari sebuah simpul (yang sejauh ini) terbaik diantara semua leaf nodes yang pernah dibangkitkan. 
Untuk mengimplementasikan algoritma pencarian ini, diperlukan dua buah senarai, yaitu: OPEN untuk mengelola node-node yang pernah dibangkitkan tetapi belum dievaluasi dan CLOSE untuk mengelola node-node yang pernah dibangkitkan dan sudah dievaluasi.

Algoritma Best First Search adalah sebagai berikut:

1. OPEN berisi initial state dan CLOSED masih kosong.

2. Ulangi sampai goal ditemukan atau sampai tidak ada di dalam $O P E N$.

a. Ambil simpul terbaik yang ada di OPEN.

b. Jika simpul tersebut sama dengan goal, maka sukses

c. Jika tidak, masukkan simpul tersebut ke dalam CLOSED

d. Bangkitkan semua aksesor dari simpul tersebut

e. Untuk setiap suksesor kerjakan:

a. Jika suksesor tersebut belum pernah dibangkitkan, evaluasi suksesor tersebut, tambahkan ke OPEN, dan catat parent.

Jika suksesor tersebut sudah pernah dibangkitkan, ubah parent-nya jika jalur melalui parent ini lebih baik daripada jalur melalui parent yang sebelumnya. Selanjutnya perbarui biaya untuk suksesor tersebut dan node lain yang berada di level bawahnya.

\subsection{Hukum Waris Islam}

Menurut Abdurrahman (2016), Hukum waris adalah hukum Islam yang mengatur pemindahan kepemilikan harta warisan dari orang yang sudah meninggal kepada ahli warisnya. Diantara hukum pokok yang harus terpenuhi dalam hal waris adalah rukun. Terpenuhi atau tidaknya rukun waris menentukan sah dan tidaknya pembagian harta warisan.

Rukun waris ada tiga:

1. Rukun pertama, adanya al-muwarrits (orang yang mewariskan) yaitu orang yang secara riil sudah meninggal atau secara hukum sudah meninggal, termasuk juga yaitu orang yang hilang dan tidak diketahui beritanya dalam waktu yang lama lalu pengadilan agama memutuskan status hukumnya telah meninggal setelah dilakukan berbagai upaya untuk mencari kejelasan keberadaan dan keadaan orang tersebut.

2. Rukun kedua, adanya al-warits (ahli waris) yaitu orang yang memiliki hubungan penyebab waris dengan al-muwarrits. Hubungan itu bisa hubungan darah (nasab), pernikahan yang sah, pembebasan budak dan wasiat. Syaratnya al-warits harus samasama beragama Islam seperti al-muwarrits dan tidak ada penghalang. Ahli waris yang ada tidak selalu menerima harta warisan, sebab para ahli waris yang lebih dekat kepada pewaris menutup yang lebih jauh berdasakan urutan atau nasabnya. Terdapat lima belas orang laki-laki dan sepuluh orang perempuan yang berhak menjadi ahli waris.

Ahli waris dari golongan laki-laki adalah

1. Anak laki-laki,

2. Bapak,

3. Suami,

4. Cucu laki-laki (dari anak laki-laki) dan seterusnya ke bawah,

5. Kakek (dari pihak bapak) dan seterusnya keatas,

6. Saudara laki-laki sekandung,

7. Saudara laki-laki seayah, Saudara laki-laki seibu,

8. Anak laki-laki dari saudara laki-laki (keponakan) sekandung,

9. Anak laki-laki dari saudara laki-laki (keponakan) seibu,

10. Paman (saudara kandung bapak),

11. Paman (saudara bapak seayah),

12. Anak laki-laki dari paman (saudara kandung ayah),

13. Anak laki-laki dari paman (saudara bapak seayah),

14. Laki-laki yang memerdekakan budak. 
Sedangkan ahli waris dari golongan perempuan adalah

1. Anak perempuan,

2. Cucu perempuan (dari anak laki-laki) dan seterusnya ke bawah,

3. Ibu,

4. Istri,

5. Nenek (ibu dari bapak) dan seterusnya keatas,

6. Nenek (ibu dari Ibu),

7. Saudara perempuan sekandung,

8. Saudara perempuan seayah,

9. Saudara perempuan seibu,

10. Perempuan yang memerdekakan budak.

3. Rukun ketiga, adanya al-muwruts (harta yang diwariskan) adalah seluruh harta dalam berbagai bentuk yang menjadi al-muwarrist semasa hidup menjelang al-muwarrits meninggal. Harta waris itu mencakup pula semua hak finansial yang menjadi hak almuwarrits menjelang al-muwarrits meninggal, diantaranya biaya pemakaman, wasiat dan zakat maal.

\section{Analisa dan Perancangan Sistem \\ 3.1 Diagram Alir Data}

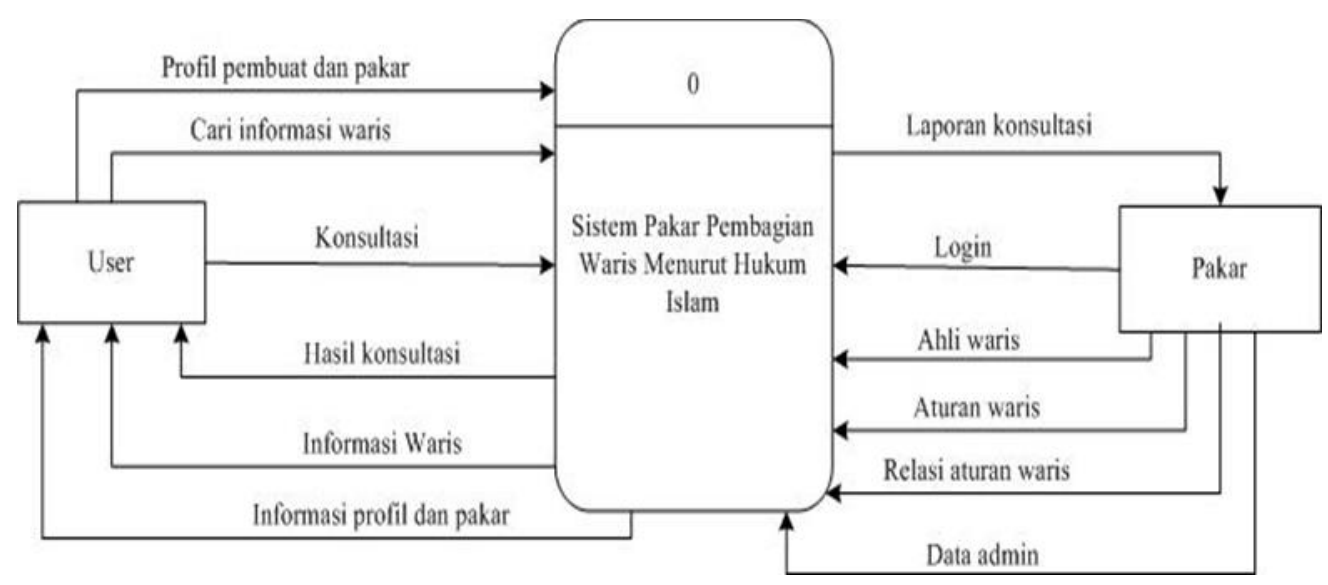

Gambar 1. Digram Konteks

Pada Gambar 1, User dapat melakukan beberapa aktivitas masukan ke sistem pakar pembagian harta waris, aktivitas tersebut antara lain konsultasi, cari informasi waris, dan melihat profil pembuat aplikasi sistem pakar dan pakar. Kemudian sistem akan memproses permintaan masukan dari user dengan cara memberikan output berupa hasil konsultasi, hasil informasi dan informasi pembuat sistem pakar dan pakar.

DAD level 0 adalah penjabaran dari diagram konteks. Pakar memiliki hak akses untuk menginputkan data-data yang diperlukan oleh sistem pakar pembagian harta warisan. User memiliki hak akses untuk mendapatkan kesimpulan dari konsultasi yang dilakukan pada sistem pakar tersebut 


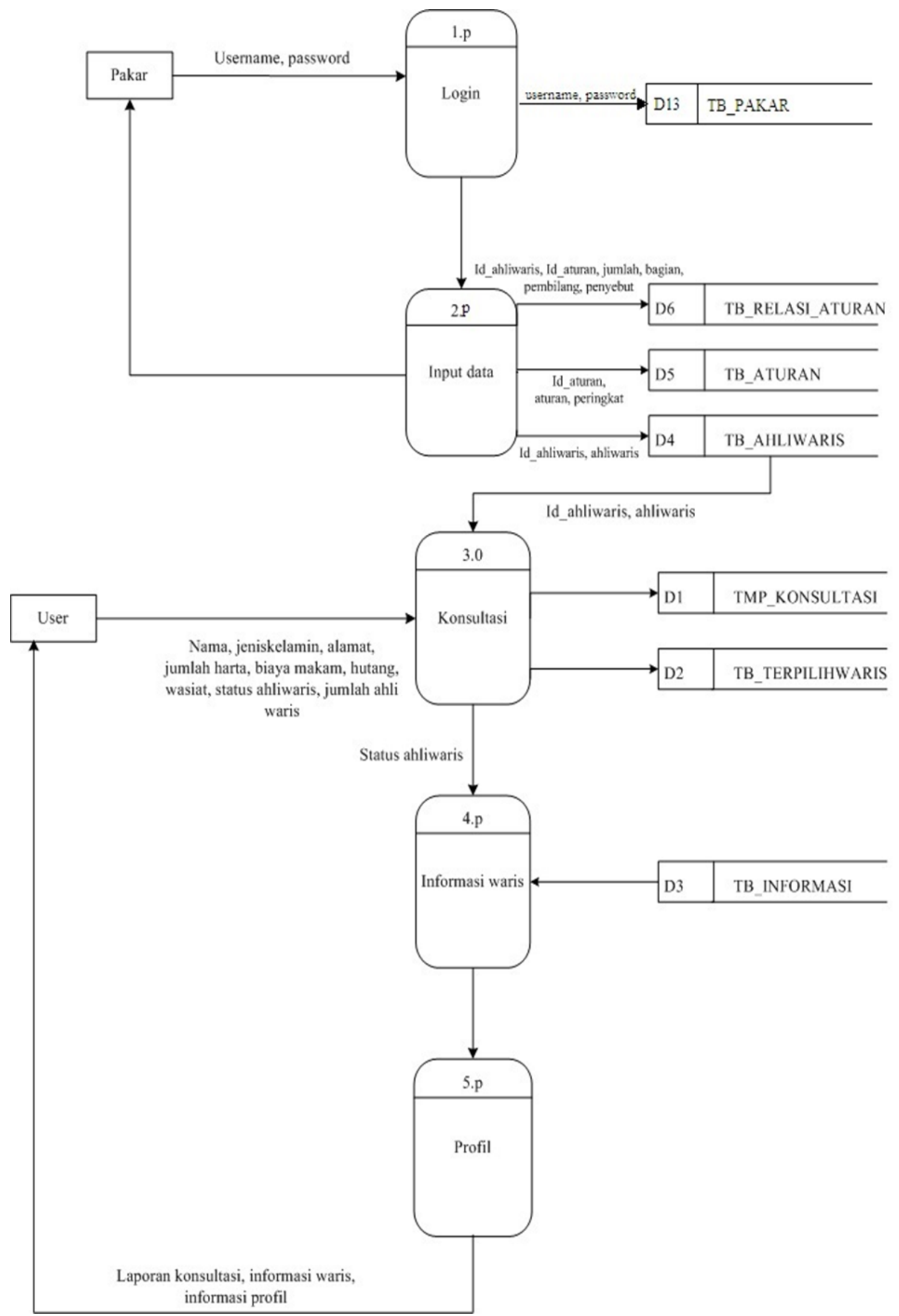

Gambar 2. DAD level 1 
4. Implementasi dan Pembahasan

4.1. Pencarian Pembagian Ahli Waris

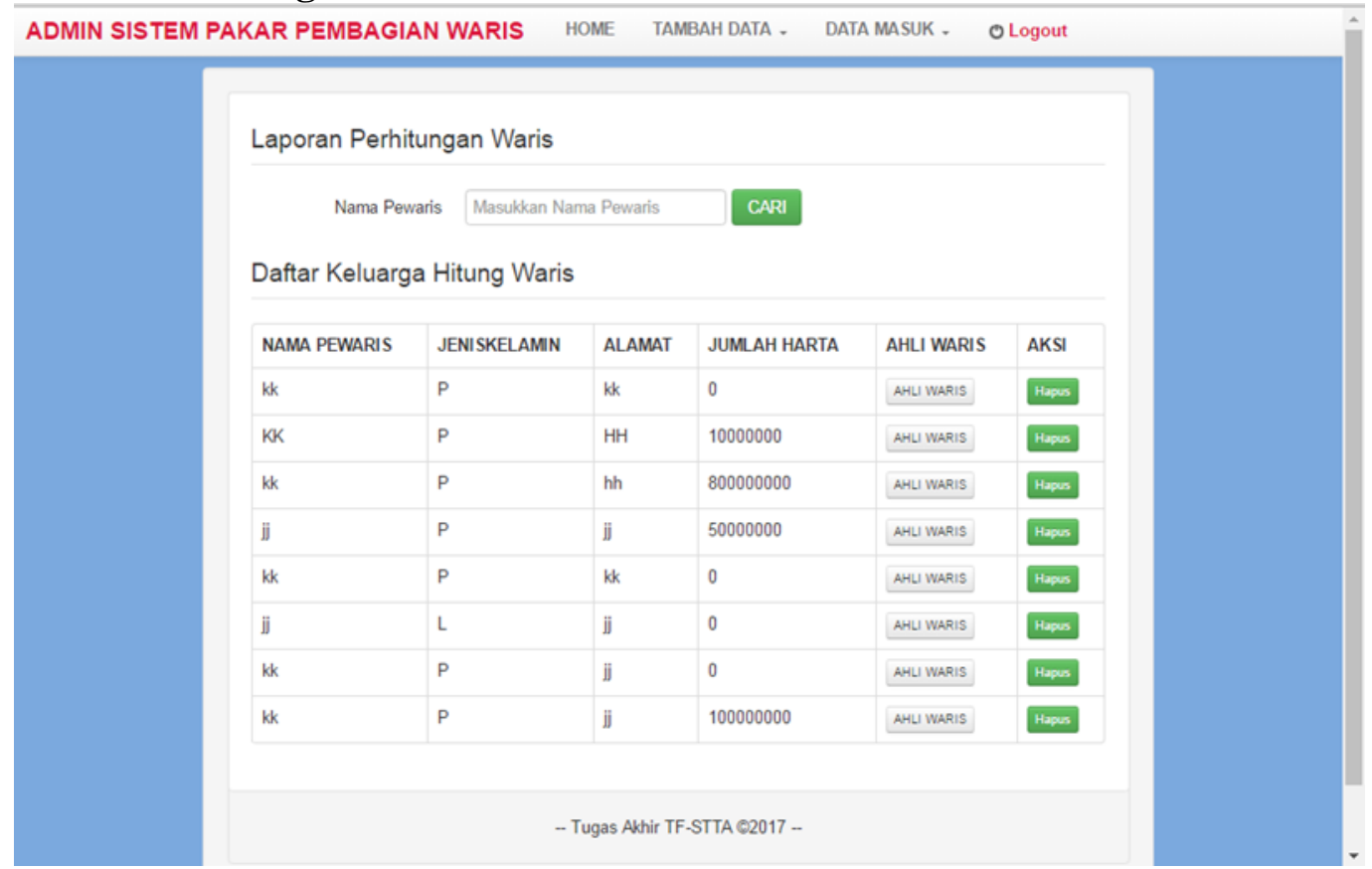

Gambar 3. Form Hasil Perhitungan

Langkah-langkah untuk pencarian bagian ahli waris antara lain sebagai berikut:

1. Menentukan ahli waris yang terhalang. Untuk menentukan ahliwaris yang terhalang yaitu menelusuri aturan-aturan yang menjadi sebab penghalang hingga mendapatkan solusi berupa ahli waris yang terhalang. Ahli waris yang terhalang tidak ada, karena aturan-aturan sebab penghalang tidak terpenuhi.

2. Menentukan bagian masing-masing ahli waris menurut aturan Islam. Untuk menentukan bagian masing-masing ahli waris sistem pakar menggunakan algoritma best first search. bagian istri seperdelapan, ibu seperenam, bapak seperenam, seorang anak perempuan setengah dan cucu perempuan keturunan anak laki-laki seperenam.

Pencarian bagian ahli waris dengan algoritma best first search sebagai berikut:

1) Mulai dengan open yang membangkitkan keadaan awal sebuah node yaitu node Aw1.

2) Bangkitkan semua successor yang ada dalam node Aw1 dan pilih simpul terbaik yaitu Aw15, Aw16, Aw23, Aw4 dan Aw17. Aw15 adalah simpul anak perempuan, Aw16 adalah simpul cucu perempuan keturunan anak laki-laki, Aw23 adalah simpul istri, Aw4 adalah simpul bapak dan Aw17 adalah simpul ibu.

3) Ulangi dari langkah 1 (pertama) sampai semua node telah dibangkitkan dan dipilih harga node yang paling minimal untuk setiap successor dan node, seperti pada Gambar 4. Langkah 2.

4) Demikian seterusnya sampai semua node selesai atau ditemukan node tujuan seperti pada Gambar 5. Langkah 3 yaitu 1/2,1/6,1/6,1/8,1/6 

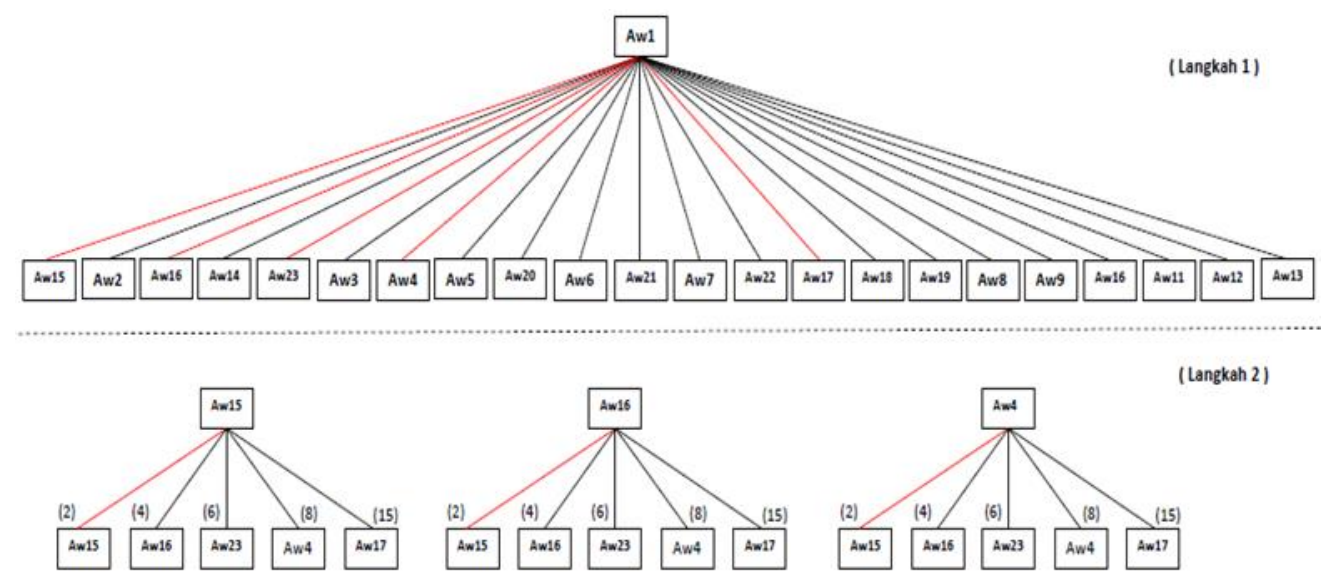

( langkah 2)

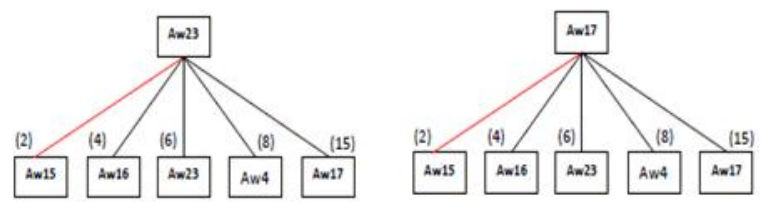

Gambar 4. Langkah Dua
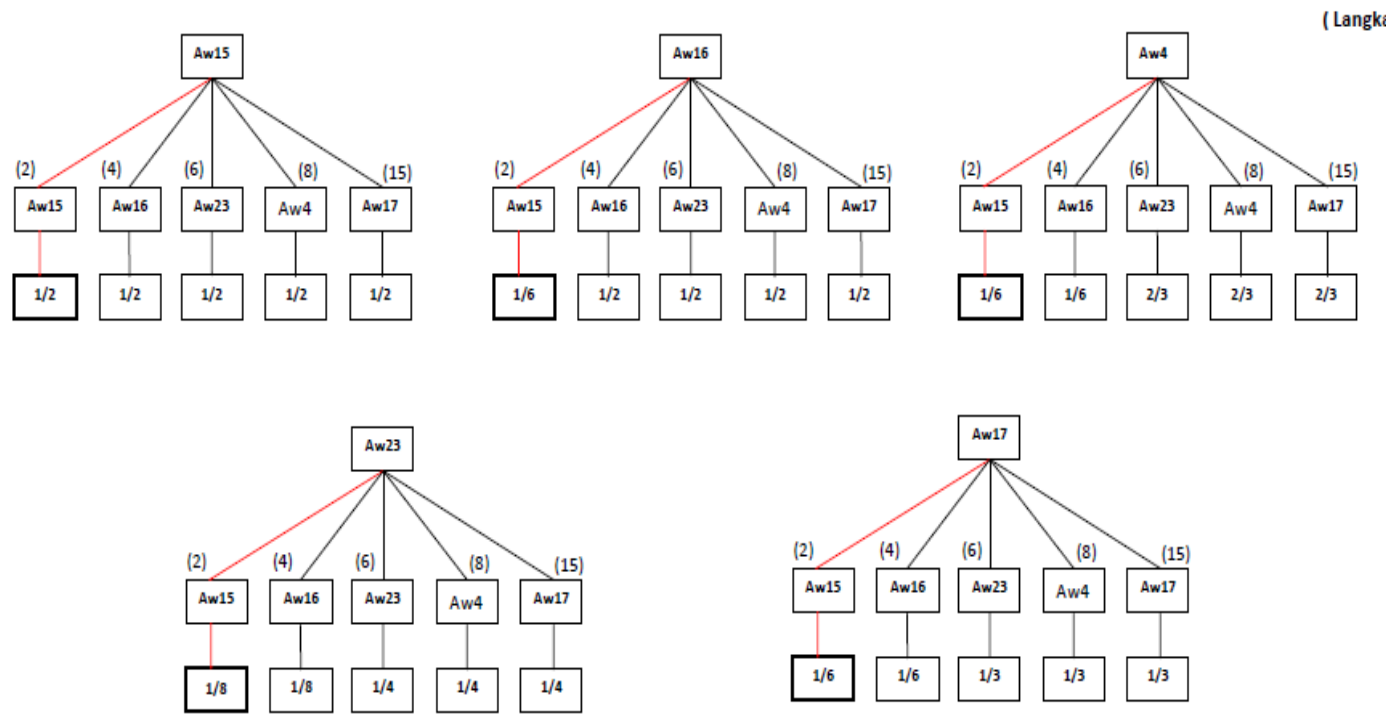

Gambar 5. Langkah Tiga

Pada sistem pakar ini menggunakan inferensi forward chaining dan algoritma best first search. Inferensi dengan metode forward chaining dapat dilihat pada penelusuran aturan-aturan yang menjadi sebab ahli waris terhalang yang mendapatkan solusi berupa ahli waris yang terhalang. Begitu juga pada penelusuran aturan-aturan ahli waris yang menjadi sebab ahli waris mendapatkan bagian masing-masing sesuai dengan aturan Islam. Solusi yang didapat berupa bagian ahli waris sebesar setengah, seperempat, sepertiga, seperenam, seperdelapan dan duapertiga.

Pencarian dengan algortima best first search pada sistem pakar ini dapat dilihat pada seleksi harga node yang paling minimal untuk setiap successor dan node. Pada Gambar 4 hal tersebut dapat dilihat. Sehingga pada pencarian dengan algoritma best first search tidak perlu menelusuri semua node yang ada tetapi hanya menuju node tujuan yang sesuai jalur aturan dan harga node yang paling minimal menuju node tujuan. 


\section{Penutup}

\subsection{Kesimpulan}

Berdasarkan hasil implementasi dan analisa hasil sistem pakar menentukan pembagian harta warisan menurut hukum Islam dengan algoritma best first search menghasilkan kesimpulan sebagai berikut:

1. Aplikasi sistem pakar ini berbasis web yang dapat membantu user untuk melakukan pembagian harta warisan yang biasanya rumit dilakukan dengan manual.

2. Aplikasi sistem pakar ini dapat menyeleksi hutang lebih besar dari harta warisan dan wasiat lebih besar dari sepertiga harta warisan.

3. Dengan metode forward chaining dan algoritma best first search pada sistem pakar ini, menghasilkan penelusuran bagian ahli waris dengan efisien.

Hasil konsultasi pada sistem pakar menampilkan data diri lengkap yang mewariskan hartanya serta menampilkan rincian pembagian harta warisan menurut aturan Islam.

\section{Daftar Pustaka}

[1] Abdurrahman, Yahya,2016.Ilmu Waris Praktis.Bogor:Al-Azhar Freshzone Publising.

[2] Afijal. 2012. Sistem Pakar Pendukung Keputusan Pembagian Harta Warisan Menurut Hukum Islam Menggunakan Visual Basic 6.0. Volume:3, Nomor : 9 ,Universitas Putra Indonesia (UPI) "YPTK" Padang.

[3] Alatas, Husein,2013.Responsive Web Design dengan PHP \& Bootstrap.Yogyakarta:Lokomedia.

[4] Ash-Shabunim, M.Ali,2013. Hukum Waris dalam Islam. __PT. Fathan Prima Media.

[5] Basyir, Ahmad Azhar, MA,2001. Hukum Waris Islam, Yogyakarta : UII Press

[6] Kenneth E. Kendall, Julie E.Kendal.2002.System Analysis and Design.New Jersey:Upper Saddle River.

[7] Kusrini.2006.Sistem Pakar Teori dan Aplikasi, Yogyakarta: ANDI Offset

[8] Kusumadewi, Sri,2003.Artificial Intelligence(teknik dan aplikasinya).Yogyakarta:Graha Ilmu

[9]Nugroho, Bunafit.2014.Aplikasi Sistem Pakar dengan PHP \& Editor Dreamweaver.Yogyakarta:Penerbit Gava Media.

[10]Nugroho, Bunafit.2013.Dasar Pemograman Web PHP-MySql dengan Dreamweaver.Yogyakarta:Penerbit Gava Media.

[11] Ridwan, Dini, Cepy .2012. Perancangan Sistem Pakar untuk Pembagian Waris Menurut Hukum Islam (Fara'id).Volume:9, Sekolah Tinggi Teknologi Garut

[12] Russell, Stuart J.;Norvig, Peter.2003.Artificial Intelligence: A Modern Appoarch(2nd ed.), Upper Saddle River, New Jersey: Prentice Hall, ISBN 0-13-790395-2

[13] Suyanto,2014.Artificial Intelligence,Bandung:Informatika Bandung 
[14] Suryadi.2014. Perancangan Aplikasi Perncarian File Dengan Menggunakan Metode Best First Search. Volume:2, Nomor : 2. J. Informatika AMIK-LB

[15] Ridwan, Dini, Cepy .2012. Perancangan Sistem Pakar untuk Pembagian Waris Menurut Hukum Islam (Fara'id).Volume:9, Sekolah Tinggi Teknologi Garut

[16] Wilson, B.1998.The AI Dictionary, URL: http://www.cse.unsw.edu.au/ billw/aidict.html 